\title{
$C^{-1} \begin{aligned} & \text { CONGRESO } \\ & \text { INTERNACIONAL }\end{aligned}$ \\ SOBRE \\ LF_O FOTOGRAFÍA
}

Congreso Internacional sobre Fotografía

UPV, 5 y 6 octubre 2017

Doi: http://dx.doi.org/10.4995/CIFo17.2017.6673

ISBN: 978-84-9048-604-7

\section{Educando en el Lenguaje Fotográfico: Algunos aportes sobre el Lenguaje Fotográfico desde las perspectivas Investigación en Artes Visuales, Investigación Basada en las Artes e Investigación Educativa y Pedagógica}

\author{
Xabier Salazar Muguerza \\ xabiersalazar1@gmail.com
}

\begin{abstract}
The aim of this project is to design a work proposal in Secondary Education in order to contribute to generate a critical visual awareness among the young. In order to achieve this aim, I will work on the Visual Thinking Strategies method and the perspective of Image as Epistemology, working on their disagreements and combining them in the artistic-educational proposal, which is based on the consumption and production of photographic images. In addition, based on this workshop proposal, a line of research has been designed within the perspective known as Art Based Reseach (largely through photography), whose main aim is to rethink the self artistic/research/teaching practices.
\end{abstract}

Keywords: Visual Language, Photographic Language, visual culture, Mass Media, Advertising, Advertising Image, Visual Thinking, Epistemic Image, Arts-Based Research, A/r/tography.

\footnotetext{
Resumen

Este proyecto tiene como objetivo diseñar una propuesta de trabajo en Educación Secundaria que contribuya a generar una conciencia crítica visual entre los jóvenes. Para ello, se trabajará sobre el método Visual Thinking Strategies y la perspectiva de la concepción de la Imagen como Epistemología, trabajando sobre sus contrariedades y combinándolas en la propuesta artísticoeducativa, la cual está basada en el consumo y la producción de imágenes fotográficas. Además, a partir de esta propuesta de taller, se ha diseñado una línea de investigación dentro de la perspectiva denominada como Investigación Basada en las Artes (en gran parte a través de la
} 

Visuales, Investigación Basada en las Artes e Investigación Educativa y Pedagógica/

fotografia), que tiene como mayor objetivo repensar las prácticas docentes/artísticas/investigativas propias.

Palabras clave: Lenguaje visual, lenguaje fotográfico, cultura visual, Medios de Comunicación de Masas, publicidad, imagen publicitaria, Visual Thinking, Imagen Epistémica, Investigación Basada en las Artes (IBA), A/r/tography.

\section{Introducción}

El documento que se presenta a continuación trata sobre un proyecto de investigación que se creó durante y a través de la experiencia vivida durante la colaboración que realicé dentro del marco del proyecto "Creadors en Residència” durante el curso 2015-2016.

Partiendo de la hipótesis de que la sociedad actual está sobrecargada de estímulos visuales (Acaso, 2009), el siguiente proyecto consiste en tratar de llevar a la práctica una investigación dentro de un centro educativo de Educación Secundaria en el que he desarrollado mis prácticas profesionales.

Esta investigación pretendo desarrollarla en dos partes:

La primera parte consiste en trabajar el lenguaje visual como un lenguaje más en la escuela. En relación a esta idea, Humberto Orozco plantea que "en la educación no podemos prescindir de las expresiones discursivas y la presencia de la fotografía para el conocimiento y la construcción de las identidades y los valores culturales" (Orozco, 2002). John R. Whiting, por su parte, plantea que “...like a good picture, should have impact, details to be seen and talked about, the quality of being remembered" (Whiting, 1979).

Partiendo de estas ideas, y precisamente porque las imágenes tienen impacto, es por lo que debe educarse en el lenguaje visual. Pero, ¿cuál es la razón por la que el lenguaje matemático o el literario son considerados temas de importancia en la escuela, y sin embargo el visual no (o al menos en su mayoría)?, y ¿cuál es la razón por la que se expone que existe un lenguaje visual en relación a las imágenes fotográficas?

Para dar respuesta a esta pregunta, en primer lugar será necesario revisar la obra de Rudolph Arnheim, y en segundo lugar, las imágenes fotográficas son consideradas como un lenguaje visual dado que, como explica John R. Whiting "the structure of a picture story is never different from that of any other type of visual or aural communication" (Whiting, 1979).

Con el objetivo de apoyar la idea de lo visual como lenguaje, María Acaso (2009) en su libro La educación artística no son manualidades compara lo visual con el lenguaje escrito, afirmando que lo que se dice a través de las imágenes no se puede decir con los demás lenguajes. 
No es posible separar este tema de estudio de la línea de pensamiento denominada como Visual Thinking. A partir de ella, después se desarrolló un método educativo denominado Visual Thinking Strategies o Visual Thinking Curriculum, el cual, aunque problematizaré más adelante, ofrece características útiles para la propuesta artístico-educativa diseñada, tales como la alfabetización visual, la cual es indispensable para desarrollar nuestras capacidades como espectador y como interesados en arte (Yenawine, 2001).

La razón por la que se ha escogido a los medios de comunicación de masas y la publicidad como productores de imágenes es la construcción de género y del cuerpo ideal que difunden, las cuales tienen un gran impacto en los adolescentes, por lo que la una de las finalidades de este proyecto es contribuir al desarrollo de una conciencia crítica visual (Acaso, 2009) por parte de los jóvenes (y mía), además de la creación de micronarrativas (Acaso, 2009) a través de la fotografía. Para ello, se pondrán en práctica algunos aspectos propios de la metodología Visual Thinking Strategies/Curriculum, tales como el consumo detenido de imágenes y las discusiones grupales. Sin embargo, y en contraposición al método V.T.S., las preguntas y discusiones planteadas no se coordinarán cuidadosamente para llegar a un resultado previamente establecido.

En relación al enfoque que se tiene de la imagen en la propuesta educativa, es imprescindible explicar que esta investigación propone trabajar desde un enfoque que promueva la "imagen como epistemología", es decir, entendiendo que la imagen como creadora y productora de conocimiento.

Por otro lado, es imprescindible explicar que el proyecto artístico-educativo que se presenta es una propuesta para los estudiantes y para mí, a través de la cual se pretende realizar una investigación basada en la perspectiva Art Based Research, además de hacer uso de la perspectiva performativa y la tendencia $\mathrm{A} / \mathrm{r} /$ tography, propias de la perspectiva IBA. La razones por las que la IBA me ha escogido como investigador son que trata de desvelar aquello de lo que no se habla (Barone \& Eisner, 2006); el rol del investigador es el de alguien que está dentro de la problemática (Hernández, 2008), y que, Según Weber y Mitchell (2004), la IBA aporta, entre otras cosas, reflexividad, la capacidad de capturar lo inefable. En relación a dicha reflexividad, se planteará una línea de investigación dentro del marco de la IBA, y a través de la fotografía, en la que el propio sujeto investigador, es el sujeto investigado.

En relación al uso y la producción de productos visuales artísticos durante todo el proyecto, y con el fin de exponer la base de esta característica de la propuesta, es necesario explicar lo que Briesen (2014) expone en su artículo Epistemic Aims and Pictorial Art: “.... an interesting feature of pictorial art, which in a certain sense can be considered conducive to our quest of achieving the epistemic aim of (objective) understanding as we have characterized it above" (Briesen, 2014). En relación a esta idea, y tal y como se expondrá más adelante en este texto, aunque para esta propuesta no sea un objetivo el hecho de conseguir una comprensión objetiva, la comprensión sí es uno de los objetivos de la perspectiva de investigación escogida.

Finalmente, resulta imprescindible explicar que mi posicionamiento como investigador es el de la tendencia metodológica $\mathrm{A} / \mathrm{r} / \mathrm{t} / \mathrm{ography}$, en la cual se propone comenzar a entendernos como un todo que abarca el ser docente, investigador y artista a la vez (Viadel, 2011), además de investigar también el "self", es decir, a uno mismo (Hernández, 2008).

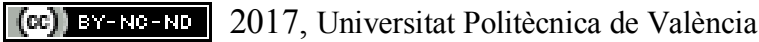




\section{Objetivos}

- Diseñar una propuesta artístico-educativa a través de la cual poder contribuir en generar una "conciencia crítica visual" entre las personas participantes en la propuesta.

- Diseñar una línea de investigación para repensar prácticas artísticas/investigativas/docentes dentro de los marcos de la perspectiva IBA, la perspectiva performativa propia de la IBA y la tendencia $\mathrm{A} / \mathrm{r} / \mathrm{t} /$ ography.

- Repensar el acercamiento y la inmersión en el arte, y en particular en el arte contemporáneo, de los jóvenes y las prácticas de producción de arte contemporáneo por parte de los jóvenes en contextos de creación artística en el marco de la Educación Secundaria Obligatoria.

\section{Desarrollo de la innovación}

\subsection{Bases teóricas de la investigación}

En primer lugar, ocuparé el concepto de "epistemología" para finalmente llegar al concepto de "imagen epistémica", es decir, la concepción de la imagen como conocimiento y productora del mismo.

Hablar de epistemología, o la teoría del conocimiento, supone plantear preguntas como ¿qué es el conocimiento? o ¿cómo podemos conocer?

En relación a esta idea, y con el objetivo de presentar mi proceso de aprendizaje tal y como ha sido el camino que he recorrido pasando por diferentes conceptos e ideas, optaré por un ejemplo filosófico más que por una definición para concebir el concepto de epistemología.

Harald Klinke (2014) en su libro Art Theory as Visual Epistemology plantea la "Alegoría de la Caverna" de Platón como una epistemología en la cual hay tres fases de comprensión: la primera fase es interpretar las meras sombras, la segunda fase es comprender que esto son solo sombras, y la tercera fase es captar las ideas que están detrás del mundo aparente. Como Klinke explica en su libro, para Platón, esas ideas, y no el mundo material, son la forma "más alta" de realidad y constituyen el conocimiento real. En relación a Platón y su concepción sobre el arte y su relación con las ideas de las que hablaba en la "Alegoría de la Caverna", expuso que los artistas están "separados" de las ideas y que solamente son capaces de producir semejanzas de la naturaleza. Desde la Teoría del Arte, en cambio, y en contraposición a las ideas de Platón, se ha luchado fuertemente con el fin de probar que las imágenes también son capaces de representar “ideas más altas" (Klinke, 2014).

Una vez presentada la posición de la Teoría del Arte, podemos pensar, por lo tanto, que debe existir una Epistemología Visual, pero, ¿qué puede llegar a significar y a abarcar este concepto?

Como explica Klinke (2014), el artista Inglés y presidente de la Royal Academy en Londres Joshua Reynolds, en contraposición a la postura de Platón hacia las capacidades del artista, desarrolló una Epistemología 
principalmente Visual, a través de la exposición de cómo un artista desarrolla las ideas: en primer lugar, el artista examina la naturaleza crea una idea de ella a través de la comparación y la contemplación; en segundo lugar, el artista extrae un archivo de imágenes mentales idealizadas; y, en tercer lugar, una vez a acumulado un número de esas ideas, el artista es capaz de hacer una combinación de ellas sobre el lienzo y hacer una abstracción de la naturaleza, en vez de copiarla.

Como Joshua Reynolds explica (1959), cuando una historia es relatada, todo ser humano forma una imagen en su cabeza, y la fuerza para representar esa imagen mental es a lo que llamamos la "Invención del Pintor". El objetivo de esas pinturas es dirigirse a la mente del espectador y comunicar estas imágenes mentales mediante medios visuales (Klinke, 2014). Esta labor mental ya la hacían los antiguos artistas; el artista contemporáneo, en cambio, puede estudiar los trabajos de los antiguos artistas y añadir sus ideas a su archivo mental, para después hacer uso de esas ideas visuales junto con su propia contribución al dominio público del conocimiento que se publica visualmente (Klinke, 2014).

En relación a esa idea, al igual que desde el Arte como expone Klinke (2014), López Cantos (2015) en su artículo La Simulación y Representación de Modelos y Teorías Científicas mediante Imágenes, expone desde la Ciencia que las imágenes epistémicas son representaciones con la capacidad de producir conocimiento que es desconocido hasta el momento (López Cantos, 2015), y de esta forma contribuir al dominio público del conocimiento.

Hasta ahora hemos estado hablando de conceptos como "ideas visuales”, pero ¿qué es el Visual Thinking?

Para comprender el Visual Thinking, es imprescindible trabajar con las ideas de Rudolph Arnheim. Como podemos ver en su libro Visual Thinking, Arnheim (1969) trata y expone la importancia de la percepción en el desarrollo y en el pensamiento del ser humano. En esta obra, Arnheim expone y muestra que la percepción y el pensamiento colaboran en los procesos de cognición de los seres humanos, y explica que si existiera una división entre ellos la cognición sería incomprensible. Dicho de otra manera, si no fuera por los sentidos, la mente no tendría con qué pensar.

Habiendo tomado la "Alegoría de la Caverna" como base para la comprensión y uso del concepto de epistemología, es importante explicar que, según Platón, las imágenes sensoriales estaban fuera del sistema de realidad, y, por ello, su filosofía está caracterizada por una desconfianza hacia la percepción.

En relación al conocimiento, Arnheim (1969) plantea que el pensamiento no es una característica exclusiva de los procesos mentales superiores a la percepción, sino al contrario, forman parte de la percepción. De esta forma, concluye que no puede eliminar el "pensar" de la percepción (Arnheim, 1969). Así, concluye que la percepción visual es pensamiento visual. Teniendo esto en cuenta, y en relación a la educación, Arnheim explica que los sentidos y el arte están separados de las palabras y los números, y la razón por la que se descuidan las artes es que están basadas en la percepción, dado que se cree que la percepción no incluye al pensamiento.

Como expone Klinke (2014), Arnheim explica que el acto de "ver" no es un proceso unidireccional, sino que incorpora una retroalimentación de la experiencia y la creación de predicciones. 
En relación a esta idea, Barthes (1989) en su libro La cámara lúcida: nota sobre la fotografía nos habla de la noción de punctum (Barthes, 1989) a través fotografía en la que aparecía un violinista cíngaro ciego, el cual era guiado por un niño. Con el objetivo de tratar la noción de punctum, Barthes (1989) cuenta cómo lo que a él le "punza" de esa fotografía es la tierra batida, la cual le produce la sensación de estar en Europa central, reconociendo las aldeas por las que pasó en sus viajes por Hungría y Rumanía. De esta forma, el hecho de que la percepción sea subjetiva es lo que hace que no se pretenda acercarnos a la objetividad en este trabajo.

Retomando la "Alegoría de la Caverna" de Platón como un sistema de epistemología, y considerando el captar las ideas detrás del mundo aparente como objetivo, resulta imprescindible tener en cuenta a William Blake, quien exponía que la producción de imágenes no era solo un simple proceso de externalización de imágenes internas, sino que el proceso de dibujar y pintar era clave en el proceso de pensamiento (Klinke, 2014). Teniendo esto en cuenta, Klinke (2014) expone que no es la percepción a solas lo que nos hace captar a los seres humanos la realidad y obtener ideas sobre el mundo en algún tipo de orden, sino el complejo proceso de crear imágenes (Klinke, 2014).

Esta última idea nos lleva directamente al tratamiento de la imagen epistémica. Harald Klinke (2014) expone que las imágenes epistémicas son imágenes que contienen algo más que lo simplemente visible, esto es, una procesada mayor comprensión del mundo, en otras palabras, conocimiento. Hans Belting, a través de las ideas de Cassirer, concluyó que la cuestión sobre las imágenes y su contenido epistémico conduce al ser humano, quien percibe, imagina y crea imágenes. Dicho esto, el poder de las imágenes no deriva de las imágenes en sí mismas, sino de los seres humanos, que les dan significado (Belting, 2001).

En relación a esta idea, desde la antropología Francisco José Sánchez Montalbán (2006), expone que tanto el estudio como la práctica de medios de producción grafica colaboran en generar posibilidades para la creación de materiales de investigación y casos a analizar.

En relación a esta última idea, los profesores Kerry Freedman y Richard Siegesmund (2015) plantearon una propuesta titulada Images as research: Creation and interpretation os the visual en la primera Conferencia Anual sobre Investigación Basada en las Artes e Investigación Artística de Barcelona. En dicha propuesta, plantearon cinco modos de entender cómo la investigación educativa basada en las artes utiliza los materiales visuales y las imágenes que documentan estos procesos: Imagen como registro: Analizar lo que se puede ver; Imagen como datos: El análisis de la cultura visual; Las imágenes como Estudio: Los participantes crean y utilizan las imágenes de forma interpretativa como una forma de investigación; Imagen como Teoría: El investigador crea un objeto interpretativo / provocativo para el análisis personal; Imagen como informes de investigación: Una representación pública de los resultados de la investigación.

Esta utilización de la imagen con el objetivo tanto de construir y deconstruir conocimiento, como de transmisión de conocimiento en investigación es la razón por la que el proceso de investigación ha llevado a escoger la IBA como la perspectiva de investigación para este proyecto, cuya fundamentación expondré en el siguiente apartado. 
Este último uso de la imagen planteado también es tratado por la Antropología y la Antropología Visual en particular, y por la simulación y representación de modelos y teorías científicas. De esta forma, se puede considerar el valor epistémico de la imagen como la imagen como conocimiento y productora del mismo, es decir, no tan solo utilizar la imagen para representar y comunicar conocimiento, sino que también ha de tenerse en cuenta la capacidad de la relación entre los seres humanos y las imágenes para crear conocimiento.

Desde la antropología, por ejemplo, lo valioso de la fotografía no es ella en sí misma, sino la reflexión que se pueda crear en la relación ser humano-fotografía/fotografias (Montalbán, 2006). Tal y como explica Montalbán (2006), el hecho de hacer buen uso de una fotografía en investigación reside en la lectura que el investigador hace de la imagen, es decir, es necesario que el investigador identifique las cualidades visuales de la imagen a partir de las cuales tenga la oportunidad de generar reflexiones científicas.

Esta última idea nos transporta al análisis de los aspectos formales de la imagen, la cual es una característica del método educativo Visual Thinking Strategies o Visual Thinking Curriculum.

Este ultimo nexo, junto con el hecho de que la representación de conocimiento no es solo propia del enfoque que concibe la Imagen como Epistemología, sino que también es parte integrante del Visual Thinking, hace que dejemos de ver estas dos líneas de pensamiento como dos compartimentos estancos, y que, como investigador, comience a tener en cuenta que pueden encontrarse en algunos puntos fuertes propios de cada línea de pensamiento.

En relación a la propuesta artístico-educativa que se quiere diseñar, y retomando el Visual Thinking, ya que, como se ha explicado, no se va a dejar completamente de lado en la propuesta, es imprescindible trabajar en el método educativo propio de esta línea de pensamiento: el Visual Thinking Curriculum o Visual Thinking Strategies.

Durante los años 90 se comenzó a tener en consideración distintos enfoques en relación a la pedagogía museística (Kivatinetz \& López, 2006). Es aquí, en este replanteamiento y en esta exploración de alternativas para la educación museística, donde entran en juego métodos educativos como el Visual Thinking Strategies o V.T.S. El interés por parte de los museos por este método, el cual fue creado en el MoMA por Abigail Housen, se debe a que, dado que una de las características de su propuesta educativa es el diálogo, resulta una atractiva opción en comparación con otros métodos educativos de enfoque tradicional.

Este método educativo en sus orígenes tenía como base la concepción del arte como herramienta para enseñar a pensar, además de tener como objetivos el desarrollo de habilidades comunicativas y la alfabetización visual de niños y jóvenes (Kivatinetz \& López, 2006). En relación a la alfabetización visual como objetivo, es imprescindible explicar que, aunque se van a problematizar algunos aspectos de este método educativo, otros, tales como este objetivo, se van a tener en cuenta en la propuesta educativa diseñada, ya que, tal y como se ha dicho previamente, no se va a dejar completamente de lado.

En relación a la apreciación del arte que promueve este método, solamente se centra en analizar los aspectos formales de la obra de arte, sin tener en cuenta la influencia de los contextos culturales en los significados estéticos y en los procesos psicológicos (Kivatinetz \& López, 2006). En relación a estas ideas, es necesario 
explicar que el V.T.C. o V.T.S. expone que la construcción del conocimiento se da mediante procesos de descubrimiento autónomos, cuya fuente es la relación establecida entre cada sujeto epistemológico y su entorno inmediato. Así, este método educativo no tiene en cuenta la interacción social, por lo que se puede comprender así que entiende que los individuos producen conocimiento por sí solos, y no se tiene en cuenta la influencia de factores externos en esa producción (Kivatinetz \& López, 2006).

Así, este método educativo tiene como punto de partida una visión de progresión cuyo objetivo final es la autonomía, en lugar de considerar que la ambigüedad, las múltiples versiones y las interpretaciones propias de las artes no solo son fruto de la autonomía del espectador, sino que es necesario considerar las cuestiones que se puedan producir de la relación obra-espectador (Kivatinetz \& López, 2006). Esto nos lleva directamente a, como ya se ha explicado previamente, una de las finalidades de la consideración de la imagen como epistemología, dada la capacidad de la relación ser humano-imagen para producir conocimiento.

En relación a estas ideas, el método educativo V.T.S. propone tres vías para el crecimiento y el desarrollo mental del espectador. En su metodología, el V.T.S. propone la observación cuidadosa, el responder a una serie de preguntas y realizar discusiones grupales (cuidadosamene coordinadas por los educadores del museo). El objetivo de dichas discusiones es que los participantes expresen sus ideas y argumentos y se sientan escuchados y valorados, y encontrar los diversos significados de la obra de arte (VUE, 2001). Además, expone que también tiene como objetivo promover el pensamiento crítico y el pensamiento creativo (VUE, 2001).

Sin embargo, tal y como explican Kivatinetz y López (2006), la concepción de pensamiento crítico que se expone desde este método educativo no trabaja la reflexión por parte de los participantes, ni tampoco se ofrece a los participantes los contextos sociales, culturales, religiosos ni políticos de las obras artísticas. Dicho esto, se considera que la línea de pensamiento a la que se favorece tiene ver más bien con un pensamiento tolerante que crítico (Kivatinetz \& López, 2006), ya que no se fomenta que se cuestionen las diferentes ideas de todas las personas implicadas en el proceso (participantes, educadores y expertos del museo) (Kivatinetz \& López, 2006).

Y, en relación a la obra de arte, este método educativo lleva a pensar que la obra de arte es portadora de una verdad única que ha de descifrarse (Kivatinetz \& López, 2006), por lo que excluye todo tipo de descentramiento, problematización o conexión con el espectador en sí y su contexto (Hernández, 2006).

Esto es completamente contrario a, como ya se ha expuesto, la consideración del valor epistémico de la imagen de Hans Belting (2001), ya que, como él explica, la fuerza de las imágenes no reside en las imágenes en sí mismas, sino en el ser humano que les da significado.

De esta manera, se puede decir que este método se preocupa más por fomentar una visión del artista en los espectadores que por las distintas versiones que estos aporten (Kivatinetz \& López, 2006), así, no se espera que los visitantes aprendan a pensar por ellos mismos, sino que aprendan lo que el educador quería que aprendieran desde el principio (Hernández, 2006).

Como Kivatinetz y López (2006) explican, y en relación a la selección de las obras de arte que se consideran "adecuadas" para los participantes, V.T.S. se muestra contrario a introducir en sus experiencias todo tipo de 
manifestaciones artísticas distintas a la pintura o la escultura, excluyendo de esta forma los vídeos, las performances, las instalaciones y la publicidad, entre otros. Así, centra sus sesiones en observar únicamente obras artísticas que hayan sido elaboradas mediante procesos tradicionales, considerándolas obras de culto elevadas y legitimadas.

Finalmente, y para terminar con la presentación del método educativo V.T.S., tal y como exponen Kivatinetz y López (2006), tanto en los museos como en las escuelas, "la esencia de la educación actualmente es crear conocimiento y posibilitar significados" (Kivatinetz \& López, 2006).

A modo de conclusión, y para terminar con la exposición de este método, tal y como Kivatinetz y López (2006) exponen, el método educativo V.T.S. puede ser útil para trabajar sobre los aspectos formales de la obra (en el caso de la propuesta educativa diseñada la fotografía), pero una vez hecho esto se considera que las temáticas a tratar deben ser candentes, polémicas y críticas.

\subsection{Propuestas artístico-educativa y de línea de Investigación Basada en las Artes}

\subsubsection{Fundamentación de las propuestas}

En este momento histórico, la principal forma de construcción de la identidad en la juventud ha dejado de ser la familia y el trabajo y a pasado a ser el consumo (Bauman, 2007). Bauman (2007) afirma que la práctica de nuestra política de vida es similar a una estrategia de compra, como una búsqueda de ejemplos de vida y de experimentación de nuevas sensaciones. Es por ello que nuestra actividad no se basa en la necesidad como ocurría antes, sino en el deseo (Bauman, 2007).

Gerbner (1998) expone que las percepciones de la realidad de los consumidores de cultura visual están, sin duda alguna, influenciadas por las imágenes que se consumen a través de los medios de comunicación de masas (Ruiz, 2007) y es inevitable reconocer que aunque sea de forma mínima, cualquier comportamiento social es el resultado de múltiples variables de estos (Garrido, 2007).

Por un lado, es imprescindible explicar que los medios se desarrollan en un campo de juicios de valor estéticamente aceptables a los que los consumidores se adaptan (Sanchez, Megías \& Rodríguez, 2004).

Por otro lado, en una investigación realizada por Eva Espinar, se relata que como agentes de socialización, los medios consiguen por parte de la audiencia un proceso de conocimiento de las normas y los valores básicos de convivencia dentro del grupo al que pertenecen (Galera, 2000). Es por ello que, a través de este discurso, los medios de comunicación de masas y en especial la publicidad, consiguen crear necesidades de los deseos, encaminado al espectador hacia un consumo que se basa en la imitación (Sanchez, Megías y Rodríguez, 2004) donde se entienden las normas como algo verdadero e incuestionable (Palominos, 2006). Es por todo esto que se considera a los medios de comunicación, y a la publicidad en especial, responsables de crear y reforzar ciertos estereotipos sociales (Palominos, 2006).

Uno de los estereotipos que más se ha fortalecido por parte de los medios de comunicación de masas ha sido el estereotipo de género, es decir, las creencias que se han estipulado sobre los roles de cada sexo (Palominos 
2006). Esta categorización nació de diferencias biológicas existentes, pero la construcción de los estereotipos de género han simplificado estas diferencias dotando a cada género de roles propios, herméticos, generales y que han pasado a ser verdades absolutas (William y Best, 1990). Es por ello que, como dice Palominos (2006) el uso que la publicidad ha hecho de ellos ha sido uno de los responsables en desarrollar una relevante desventaja en las mujeres sobre los hombres y ha logrado que las mujeres sean una minoría cultural (Tajfel, 1981). Además, como Sandra L. Calvert (2008) mantiene en su artículo Children as Consumers: Advertising and Marketing, la fuerte difusión de las campañas publicitarias está llevando a la sexualización y explotación de chicas jóvenes (Calvert, 2008). En esta línea, en el libro La educación artística no son manualidades (Acaso, 2009), la autora mantiene que las supremacías de género son unos ideales que se transmiten mediante el lenguaje visual de forma implícita y aparentemente inofensiva pero con un gran impacto en la sociedad. Además, tal y como expone Acaso (2009), que el impacto de los medios de comunicación de masas no depende del contenido del mensaje que transmiten o de lo verdadero del mismo, sino de lo buena que sea la imagen y la eficacia con la que se comunica (Galeano, 1998).

Es por ello, que, teniendo claro el impacto del hiperdesarrollo de lo visual en la sociedad actual, Acaso (2009) plantea que la educación artística no puede sólo preocuparse de los productos visuales artísticos, sino que ha de ampliar su horizonte y trabajar sobre todas las producciones de significado que se llevan a cabo a través del lenguaje visual, ya que los mensajes que tienen impacto en el consumidor se comunican mediante sistemas icónicos, pero de una forma inconsciente.

Acaso (2009) expone que para que el consumidor acepte y crea los mensajes emitidos por la publicidad y compre de forma desmesurada, es imprescindible que sea una persona desinformada en el campo del lenguaje visual, es decir, que no esté educado en la lectura de imágenes, por lo que no conoce ni es consciente de la potencia que tiene el lenguaje visual, y comprará sin medida.

Por ello, en este mundo caracterizado por el hiperdesarrollo del lenguaje visual y el neocapitalismo, denominado por McLaren como cultura depredadora (1997), y en el que la confusión entre realidad y representación cada vez es mayor, es necesaria la alfabetización visual de la población. Tal y como expone McLaren (1997): "En el debate educativo de nuestros días no se habla de tener una ciudadanía alfabetizada en el lenguaje de los másmedia capaz de interrumpir, contestar y transformar el aparato de estos, de manera que pierdan su poder de infantilizar a la población y dejen de crear sujetos sociales pasivos, temerosos, paranoicos y apolíticos".

En relación a la idea de alfabetización visual, y teniendo en cuenta que en este proyecto se está trabajando sobre la línea de pensamiento que concibe la imagen como epistemología, se plantearán dos definiciones planteadas por dos distintos autores:

La primera definición viene de la mano de Hortin (1980), y concibe la alfabetización visual como la capacidad para entender y hacer uso de las imágenes, además de la capacidad para pensar, aprender y expresarse a través de las imágenes. 
La segunda definición viene dada por Bonomo (1999), quien concibe la alfabetización visual como la capacidad de construir significados a partir de las imágenes visuales, para lo que el receptor hace uso de habilidades explorativas, críticas y reflexivas.

En relación a esta concepción de la alfabetización visual, María Acaso (2009) propone entender los procesos de análisis y de producción de productos visuales como procesos relacionados con la creación de conocimiento, y no solo de conocimiento, sino de conocimiento crítico.

Por ello, y con la finalidad de que toda persona tenga la oportunidad de desarrollar una línea de pensamiento propia, como explica Acaso (2009), es absolutamente necesario ir más allá de la superficie de la cultura visual de la cual estamos rodeados en nuestro día a día, y que comencemos a someter a esta cultura visual a análisis con el objetivo de darnos cuenta de qué ideas construyen en nuestro cerebro las imágenes por las cuales estamos rodeados.

Para terminar, se expondrá la fundamentación de la perspectiva de investigación que llevó a escoger el proceso investigativo, esto es, la IBA.

Dentro de esta perspectiva, resulta necesario explicar que tanto la perspectiva performativa (Hernández, 2008), como la tendencia A/r/tography (Berridge, 2007; Irwin, 2004; 2006; Irwin et al. 2006; 2007) son ejes centrales de este proyecto. En primer lugar, y en la medida en la que en este proyecto mi trabajo se centra en la producción artística, la investigación y la práctica en educación artística, el proceso investigativo ha hecho que se escoja la tendencia A/r/tography (Berridge, 2007; Irwin, 2004; 2006; Irwin et al. 2006; 2007). La razón de este ser escogido es precisamente que lo que desde esta tendencia se propone es comenzar a entendernos como un todo que abarca el ser docente, investigador y artista a la vez (Viadel, 2011), además de investigar también el “self”, es decir, a uno mismo (Hernández, 2008).

En segundo lugar, a razón por la que la investigación ha llevado a la perspectiva performativa es que esta pone énfasis en la práctica, es decir, en la acción artística, y en el rol del cuerpo dentro de las narrativas que se denominan como autoetnográficas (Hernández, 2008). Esto es algo que se ha convertido en el eje de parte la línea de investigación que se plantea en este proyecto, en la medida en que (como ya he introducido y veremos en el diseño de la propuesta) se pretenden repensar las propias prácticas artísticas/investigativas/docentes a través del cuerpo en/y la imagen.

\subsubsection{Propuestas}

En relación a la metodología de la propuesta artístico-educativa, y con el objetivo de comprender cuál sería la puesta en práctica de las metodologías, enfoques e ideas expuestas hasta ahora y su relación con la propuesta artístico-educativa diseñada, esta se dividirá en 4 partes lineales en este apartado:

En primer lugar, se trabajará a través del método Visual Thinking Strategies. Sin embargo, sólo se pondrán en práctica algunas características de este método educativo: por un lado, se trabajará sobre una serie de aspectos formales de la fotografía, tales como el soporte, los elementos narrativos, las herramientas del lenguaje visual 
que han sido utilizadas, el punctum (Barthes, 1989), y el fundido; por otro lado, y una vez se haya trabajado sobre los aspectos previamente planteados, se propondrá a los participantes que expresen sus opiniones, ideas, conclusiones, etc. sobre una serie de imágenes. Sin embargo, el objetivo de estas discusiones no es llegar a una verdad única previamente establecida por el docente/investigador/artista, sino que su objetivo es exponer una serie de conocimientos y realidades, y conocer las opiniones, ideas, conclusiones o realidades expuestas por los participantes. Además, también se trabajará en la idea de que las imágenes fotográficas no siempre tienen por qué ser lo que parecen ser, pero, una vez más, no se intentarán imponer estas ideas o mostrarlas como verdades únicas, sino que el objetivo de esta práctica será mostrar otras realidades a los participantes. Una vez trabajados estos aspectos de la fotografía, se propondrá a los participantes poner en práctica los aspectos de la fotografía trabajados.

Una vez habiendo trabajado sobre los aspectos formales de la fotografía, y tal y como proponen Kivatinetz y López (2006), a través de breves lecturas, visualizaciones de imágenes previamente escogidas y discusiones, se comenzará a tratar la problemática de que la publicidad emita y difunda mensajes y el impacto que estos tienen en nosotros, la importancia de la implicación del programa informático Photoshop, y las construcciones de género y de cuerpo ideal que la publicidad difunde.

Una vez habiendo trabajado sobre esas ideas, se propondrá a los participantes realizar un análisis propuesto por María Acaso (2009) de una serie de imágenes publicitarias. La autora propone dos análisis: el primero comienza con la clasificación del producto visual (por soporte o por función), continúa realizando un estudio del contenido (trabajando los elementos narrativos, las herramientas del lenguaje visual y el punctum, entre otros), después analiza el contexto que presenta la imagen, y, finalmente, analiza y trabaja el desvelamiento del mensaje manifiesto y latente. El segundo análisis, en cambio, partiendo de observar las imágenes, plantea a los jóvenes una serie de preguntas (tales como “¿qué estructura física alberga el producto visual?”, “¿es accesible y cuantas veces la he visto?” o “qquiénes son el autor o autores?”); continúa proponiendo diferenciar la imagen entre metanarrativa y micronarrativa (Acaso, 2009), es decir, entre si su objetivo es hacer que piense lo que otros quieren que piense, o me hace reflexionar y establecer mis propios juicios; después propone un análisis de los estereotipos, que se presentan, los mensaje(s) que emite la imagen, y la actividad consumista que desarrolla; y, finalmente, plantea la pregunta “¿me lo voy a creer?”.

Una vez habiendo trabajado sobre las realidades que se muestran en dichos productos visuales analizados, se propondrá a los participantes una discusión sobre "conociendo otras realidades ¿qué realidades "otras" podéis pensar?". A partir del planteamiento de esta discusión, se comenzaría a trabajar dentro del marco de la concepción de la "imagen como epistemología”, ya que, a partir de esas imágenes y realidades construidas y difundidas por la publicidad, se pensarían unas realidades “otras”, es decir, conocimiento.

Para terminar, a partir de esas realidades “otras" pensadas por los participantes, se les propondría crear unas imágenes "otras", de tal forma que se crearían una serie de representaciones visuales, es decir, micronarrativas, portadoras del conocimiento de cada participante. Así, los participantes habrían trabajado sobre las dos formas de la concepción de la imagen como epistemología, tal y como ya he trabajado previamente en este texto: las 
imágenes como representaciones visuales del conocimiento del autor de las mismas, y la capacidad de la relación ser humano-imagen para generar conocimiento.

Finalmente, es imprescindible explicar que, como ya se ha dicho, todas y cada una de las ideas, conceptos, y discusiones expuestas y propuestas tienen como objetivo mostrar otras realidades a los participantes y generar discusiones y debates que ofrezcan la posibilidad de generar conocimientos, pero no tienen como finalidad imponer ideas o llegar a una serie de verdades únicas o resultados previamente establecidos. En palabras de Rancière (2004), "son las obras de un artista dueño de sus propias imágenes".

Por otra parte, y en relación a la línea de investigación propuesta, es necesario explicar las siguientes tres vías de investigación:

La primera vía sería el hecho de que yo también, como docente/investigador/artista creara, con la ayuda de los jóvenes participantes, micronarrativas (Acaso, 2009). A partir de estos productos visuales, me gustaría analizar cuáles son los aspectos dentro de las problemáticas trabajadas a los cuales doy importancia, y de esta manera repensar mi práctica docente/investigativa/artística.

La segunda vía sería que yo también aparezca en las micronarrativas (Acaso, 2009), de tal forma que me gustaría analizar, a partir de esos productos visuales, mi práctica docente/investigativa/artística poniendo el foco en las relaciones que establezco con los participantes.

En tercer lugar, se plantearía llevar a cabo una documentación del proyecto. Dicha documentación se realizaría a través de la fotografía, a través de fotografías tomadas tanto por los estudiantes como por mí. A través de estas fotografías, me gustaría analizar mi actitud física, mis gestos, mi posición(amiento) y su posible revelación física como artista/investigador/docente, es decir, mi cuerpo (además de los nuevos, posibles e impredecibles caminos a los que me lleve la perspectiva performativa de la IBA a través de la fotografía).

\section{Resultados}

Partiendo de la observación y la participación llevadas a cabo en el proyecto "En Residència" de Luz Broto y otros proyectos de creación artística similares, se ha extraído el siguiente resultado:

En un proyecto que está pensado para que todos los participantes sean o se conviertan en creadores artísticos, la posibilidad de convertirse en participante activo en todo el proceso del proyecto de creación artística colaborativa, es decir, en artista que crea partiendo de sus propios procesos de pensamiento o idea/s o a partir del/los proceso/s o idea/s escogidas entre todos los artistas, depende de que el proyecto en sí sea democrático.

Este resultado se ha extraído de una serie de casos, por lo que no se pretende que sea aplicable a todos y está abierto a debate. 


\section{Conclusiones}

En primer lugar, si el resultado que se quiere obtener es capacitar a los estudiantes para valorar las imágenes que consumen en su día a día, ¿en qué medida y cómo se debe trabajar esto? Es decir, tenemos claro que, una vez trabajados estos aspectos del lenguaje fotográfico, queremos trabajar con las imágenes que mayor impacto tienen en los jóvenes de esta edad, y que algunas de estas son las relativas a la construcción de género y de cuerpo ideal, pero, ¿es suficiente esta propuesta de taller para generar una conciencia crítica visual (Acaso, 2009)? Sinceramente, creo que esta problemática, como explica Acaso (2009), se ha convertido en una responsabilidad de la Educación Artística, por lo que no sé hasta que punto puede esta propuesta puede conseguir el objetivo de generar esa conciencia crítica visual.

En segundo lugar, me gustaría tarabajar sobre las ideas de Boris Groys (2010). En su libro Volverse publico: Las transformaciones del arte en el ágora contemporánea (Groys, 2010), el autor expone cómo el arte de vanguardia es impopular y es visto como algo elitista. Comentarios relacionados con estas ideas se dieron cuando, desde la perspectiva del espectador, realizamos un debate sobre arte contemporáneo tanto los estudiantes como los colaboradores dentro del marco del proyecto "Creadors en Residència". Sin embargo, como ya he dicho, resulta imprescindible aclarar que estas ideas, tal y como lo plantea Groys (2010), son las del espectador. Teniendo esto en cuenta, me planteo la siguiente pregunta: ¿Qué pasaría si el espectador se convirtiera en artista? O más específicamente, ¿qué pasaría si a través de proyectos sociales como "Creadors en Residéncia" (planteados desde un enfoque democrático) el espectador se convirtiera en artista?

Bajo mi punto de vista, el arte contemporáneo, en tanto herramienta para la transformación social, sirve a la ideología del artista. Por lo que, ¿qué pasaría si el espectador se convierte en artista que lucha por una transformación social acorde con su ideología, es decir, si utiliza el arte de vanguardia como medio para (intentar) conseguir sus propios fines ideológicos y encuentra en dicho medio una herramienta para conseguir dicha transformación social (por muy pequeña que sea)? ¿cambiaría esto los hechos de que el arte de vanguardia sea impopular y sea visto como algo elitista?

Finalmente, en relación con las anteriores ideas, e intentando ampliar este horizonte planteado, me gustaría plantear una pregunta de investigación: ¿en qué medida el relacionarse con el Arte Contemporáneo puede hacer que desarrollemos/crezca nuestro pensamiento en relación a la transformación social? 


\section{Referencias}

ACASO, M. (2009). La educación artística no son manualidades. Madrid: Los libros de la catarata.

ARNHEIM, R. (1969). Visual thinking. Univ. of California Press.

BARONE, T. y EISNER, E. (2006). “Arts-Based Educational Research" en Complementary methods for research in education. Ep, J. Green, C. Grego y P., 1997, vol. 2, p. 75-116.

BARTHES, R. (1989). La cámara lúcida: Nota sobre la fotografia. Barcelona: Paidós.

BAUMAN, Z. (2007). Tiempos líquidos: vivir en la época de la incertidumbre. Barcelona: Tusquets.

BELTING, H. (2001). Bild-Anthropologie: Entwürfe für eine Bildwissenschaft. München: W. Fink.

BERRIDGE, R. (2007). “A/r/tography as auto/biography as palinode”. Nicklin, L. y Marshall, M. (coord). En Arts Based Educational Research Conference. Australia: University of Canberra. 1-16.

BONOMO, A., COLBERT, C., CONNER, A., GIORGIS, C., JOHNSON, N. J., KAUFFMAN, y G., KULESZA, D. (1999). “Children's books: Visual Literacy” en The Reading Teacher. Wiley, 1999, vol. 53, núm. 2, p. 146-153.

BRIESEN, J. (2014). Pictorial Art and Epistemic Aims. Newcastle upon Tyne : Cambridge Scholars Publishing.

CALVERT, S. L. (2008). "Children as consumers: Advertising and marketing” en The future of children. The Future of Children, 2008, vol. 18, núm. 2, p. 205-234.

CANTOS, F. L. (2015). "La simulación y representación de modelos y teorías científicas mediante imágenes" en THÉMATA. Revista de Filosofía. THÉMATA. Revista de Filosofía, 2015, núm. 51, p. 271-288.

FREEDMAN, K. y SIEGESMUND, R. (2015). “On Criteria in Arts-Based Education Research”. En Conference on ArtsBased Research and Artistic Research: The continuing dialogue. Porto: University of Porto. 1-25.

GALEANO, E. (1998). "Patas arriba: la escuela del mundo al revés” en Siglo XXI, 365. Boletín americanista. Siglo XXI, 365, 1998, núm. 50, p. 278-288.

GARRIDO LORA, M. (2007). "Estereotipos de género en la publicidad. La creatividad en la encrucijada sociológica" en Creatividad y sociedad: revista de la Asociación para la Creatividad. Revista Creatividad y Sociedad, 2007, núm. 11, p. $53-71$.

GROYS , B. (2010). Going public. Berlin: Sternberg Press.

HERNÁNDEZ, F. (2006). "Critical thinking at school: exploring an oxymoron" en Springer Netherlands. Springer Netherlands, 2006, vol. 7, núm. 3, p. 215-220.

HERNÁNDEZ, F. (2008). "La Investigación Basada en las Artes. Propuestas para repensar la investigación en educación” en Educatio Siglo XXI. Educatio Siglo XXI, 2008, núm. 26, p. 85-118.

HORTIN, J.A. (1980). Visual Literacy--the Theoretical Foundations: an investigation of the research, practices and theories. Northern Illinois University.

IRWIN, R. L. (2004). “A/r/tography: A metonymic métissage” en A/r/tography: Rendering self through arts based living inquiry. Pacific Educational Press, 2004, p. 27-38.

UNVERSITY OF BRITISH COLUMBIA. A/r/tography. http://artography.edcp.educ.ca [Consulta: 14 de mayo de 2016] 
IRWIN, R. L., BEER, R. SPRINGGAY, S., GRAUER, K., XIONG, G. y BICKEL, B. (2006). "The rhizomatic relations of a/r/tography" en Studies in Art Education. Southern Illinois University Carbondale, 2006, vol. 48, núm. 1, p. 7088 .

IRWIN, R. L., BICKEL, B., TRIGGS, V., SPRINGGAY, S., BEER, R., GRAUER, K., XIONG, G., SAMESHIMA, P. y RICKETTS, K. (2007). “The City of Richgate: A/r/tographic Cartography as Public Pedagogy”. En Arts Based Educational Research Conference, Bristol: University of Bristol. vol. 28, núm. 1, p. 61-70.

KIVATINETZ, M. y LÓPEZ, E. (2006). “Estrategias de pensamiento visual: ¿Método educativo innovador o efecto placebo para nuestros museos?" en Arte, individuo y sociedad. Universidad Complutense de Madrid, 2006, núm. 18, p. 209-240.

KLINKE, H. (2014). Art theory as visual epistemology. Cambridge Scholars Publishing.

MCLAREN, P. (1997). Pedagogía crítica y cultura depredadora. Políticas de oposición en la era posmoderna. Barcelona: Paidós.

MONTALBÁN, F. J. S. (2006). "La máquina etnográfica” en Contraluz: Revista de la Asociación Cultural Arturo Cerdá y Rico. Asociación Cultural Arturo Cerdá y Rico, 2006, núm. 3, p. 53-72.

MULLEN, C. (2003). "A self fashioned gallery of aesthetic practice” en Qualitative Inquiry. Sage publications, 2003, vol. 9, núm. 2, p. 165-182.

OROZCO, H. (2002). “Fotografía y educación” en Revista Electrónica Sinéctica, núm. 21, p. 84-86.

PALOMINOS, M. (2006). Presencia de estereotipos de género en la publicidad infantil: análisis de contenido. Trabajo de Investigación. Chile: Universidad de Chile, $<$ http://cybertesis.cl/tesis/uchile/2006/palominos_m/sources/palominos_m.pdf $>$ [Consulta: 18 de mayo de 2016]

RANCIÈRE, J. (2004). “Epílogo” en Depardon, R. Imágenes políticas. Madrid: Casus Belli Ediciones.

REYNOLDS, J. (1959). "Discourse IV" en Reynolds, J. Sir Joshua Reynolds: Discourses on Art. San Mariano: The Huntington Library.

RUIZ, E. E. (2007). "Estereotipos de género en los contenidos audiovisuales infantiles". Comunicar: Revista cientifica iberoamericana de comunicación y educación, Vol. $2007 \quad$ (29), pp. 129-134. $<$ https://dialnet.unirioja.es/servlet/articulo?codigo=2393087 > [Consulta: 20 de mayo de 2016]

SÁNCHEZ, L., MEGÍAS, I., y RODRÍGUEZ, E. (2004). Jóvenes y publicidad: valores en la comunicación publicitaria para jóvenes. España : INJUVE y FAD. <http://www.injuve.es/observatorio/infotecnologia/jovenes-y-publicidadvalores-en-la-comunicacion-publicitaria-para-jovenes-fad $>$ [Consulta el 20 de mayo de 2016]

SUlliVAN, G. (2004). Art Practive as Research Inquiry in the Visual Arts. New York: Teachers College, Columbia University.

VIADEL, R. M. (2011). "La investigación en educación artística”, en Educatio Siglo XXI. Educatio Siglo XXI, 2011 , vol. 29, núm. 1, p. 211-230.

TAJFEL, H. (1981). Human groups and social categories. Cambridge: Cambridge University Press. 
VUE (2001). “Comprendiendo los conceptos básicos de VTS” VUE. En VTS Estrategias de Pensamiento Visual. Centro Atlántico de Arte Moderno de Las Palmas de Gran Canaria: VUE. 1-9.

WEBER, S. y MITCHELL, C. (2004). About Arts-Based Research. Holanda: Kluwer press.

WILLIAMS, J. E. y BEST, D. L. (1990). Measuring Sex Stereotypes. California: Sage Publications.

WHITING, J. R. (1979). Photography is a Language. New York: Arno Press.

YENAWINE, P. (2001). "Iniciación al arte: ideas para la selección de imágenes" Yenawine, P. En VTS Estrategias de Pensamiento Visual. Centro Atlántico de Arte Moderno de Las Palmas de Gran Canaria: VUE. 